\title{
Interspatiality: space and the environment - a conceptual approach
}

\author{
C. James \\ London South Bank University, UK
}

\begin{abstract}
The research seeks to critique, redefine and recast the sustainability agenda through the re-examination of the links between spatial design, the environment and interdisciplinarity. It repositions the role of architecture at the centre of the debate through the reframing of these agendas, in offering a new interpretation of architecture and by problematising its capacity to respond to urgent environmental concerns such as climate change and resource depletion. The proposition for a new potential for environmental engagement through the conceptual formulation 'interspatiality' attempts to connect existing contemporary architectural and sustainability discourses and respond to emerging spatial territories such as the 'spatial turn'. The reconceptualisation of space and spatial production is explored as a key to the rethinking of blocked and restrictive architectural approaches and hitherto neglected spatio-environmental identifications. Interspatiality - the spatialisation of the environment, identifies the potential for an overarching understanding of space, spatial innovation and the environment within the city and elaborates interdisciplinary dimensions. It proposes a new spatial methodology of environmental character and signals a model for 'integral sustainability'; a more unifying, collective, inclusive and reconciliatory approach looking to a productive, creative and 'complete architecture' - one scripted to suit the emerging urban global reality. The work develops 'interspatial thinking' as a conceptual framework for assimilating new spatial identifications, theoretical approaches, design strategies and methodologies, that can resonate with both contemporary and future directions in architectural practice, research and pedagogy, collaborative, multidisciplinary and interdisciplinary modes of practice including global and local policy-makers, and private and public industries.

Keywords: interspatiality, spatiality, environment, interdisciplinarity, urbanism, sustainability.
\end{abstract}




\section{Introduction}

There is an urgent need within all areas of architectural activity to address unprecedented critical conditions of crisis - in rapid urbanisation, climate change and energy resource depletion. Normative modes of architectural production have fallen short in acknowledging the complex context in which today's key design and sustainability challenges arise. Architecture's failure to respond effectively to the environmental debate and wider socio-economic controversies is reflected in an inability to look beyond established agendas such as $\mathrm{CO}_{2}$ reduction, energy efficiency and control and seemingly incontestable, consensual definitions of green building and infrastructure. The identification of sustainability within architectural debate is deeply problematic and as Jon Goodbun observes in the Scarcity project, there is an 'inadequacy of existing concepts active in thinking about the built environment, such as sustainability' (Goodbun et al. [1]). Goodbun identifies the 'contested nature of sustainability' (Guy [2]) then asserts that new 'conceptual tools' (Goodbun et al. [1]) are now required to respond to postsustainable directions. Furthermore the environmental problematic within architectural spheres is ill-defined - the discourse 'fragmented and contradictory' (Hagan [14]) reflecting diverse and conflicting approaches, variable sustainability concerns and social, economic and resource inequities that are 'hardly ever discussed in its full complexity' (Guy [2]). His conclusion that there is still no 'conceptual and critical language up to the job' (Goodbun et al. [1]) is shared by Susannah Hagan, who attributes the issue within environmental discourse to the absence of a 'compelling, immediately identifiable formal language on which to pin the cause of environmentalism' (Hagan [14]). Whilst it is widely accepted that architects, are practising and theorising in relation to the overarching challenges captured by the term sustainability, there is no agreement in the way the challenges are framed, the way questions are asked, solutions imagined and work conceptualised and practiced. As McDonough and Braungart observe in their manifesto Cradle to Cradle 'it is not a good idea to use the kind of thinking that caused a given problem to solve a given problem' (McDonough and Braungart cited in Goodbun et al. [1]). It is a notion that demands that we re-examine orthodoxies, re-evaluate responses and rescript appropriate dialogues within all areas, to address the widely felt but poorly-defined aspiration to meaningfully position sustainability at the heart of architecture.

This paper seeks to critique and reframe the environmental agenda within architecture, reconceptualising environmental issues through the motif of spatial innovation in architectural theory and practice. It presents 'interspatiality' as a conceptual formulation with the primary aim of exploring ways in which we can respond to and reorient strategies within the sustainability agenda and redefine key sustainability issues of explicit architectural and environmental concern. Interspatiality proposes the possibility of repositioning of architecture as central to the discussion concerning sustainability and reframes its role within interdisciplinary dimensions. 


\section{The problematic}

\subsection{Global urban challenges}

Challenges such as the growth and intensification of urban environments and coincidence of socio-economic and environmental crises are both complex and unprecedented. Our understanding of shared global, local and human context is increasing and with it a shift towards a recognition of the interconnectedness of earth and energy systems - as Lefebvre observes 'the symbiosis - in the sense of exchange of energy and materials, between nature and society' (Lefebvre [4]). Our acknowledgement of the impact of human intervention on global climate and earth as an integrated system is developing and with it an appreciation of a symbiotic relationship that is in a constant dynamic, where human needs, energy, physical and environmental space are balanced and linked in a fragile interconnected state. Global environmental burdens however are not equitable, and the impact of crises and conditions such as emissions wealth and access to resources are experienced differently in diverse parts of the world, particularly in the global south defined by climate change. The shared challenges ahead are largely contested, bound in a complex weave of global and local, environmental and architectural considerations that necessarily demand diverse cross-disciplinary approaches. An example can be seen in rapid urbanisation with over half of the world's population living in urban areas, bringing changes in the relationships between local and global conditions and in turn transforming our identifications of the issues. Significantly in architectural terms, globalisation has contributed to the homogenisation, explored later in this discussion, of the built environment particularly within our cities, in the creation of 'placelessness'(Tuan [5]) - the loss of meaning of place, where notions of 'localisation', location and the specificity and relationship of place and time have been eroded. The fundamental argument presented here is can the re-conceptualisation of spatiality and the environment be deployed to address sustainability and urbanism issues such as these - for example by simultaneously grounding architecture whilst engaging with a shared, expansive, complex and multifarious global context in its reconnection of place to 'locus'?

\subsection{The problematic}

This paper seeks initially to formulate and elaborate understandings of the problematic. It identifies a critique, by problematising the issues of sustainability within architectural praxis in relation to the city and urban approaches. The discussion can be characterised by four issues that will be explored as follows:

Compensatory and retroactive approach;

Commodification, 'iconism' and homogeneity;

Technology, efficiency and the environment;

Autonomy and disconnection. 
The debate surrounding sustainability issues and particularly the environmental problematic within architectural spheres such as theory, practice and pedagogy, have become increasingly restricted, blocked and in some cases immobilised. This can be in the most part attributed to the narrowness of the discussion - focused on solution-based compensatory or remedial efforts, driven by the commodification of architectural production, limited to technological advancements and efficiency and restricted to autonomous architectural thinking. These limitations coupled with a tendency to seek a formal or stylistic language, aligned to notions of homogenised 'object'-building and iconic-based aesthetic or form that 'privileges the visual' (Till [11]) and branding; the quick-green-bling-fix. The key challenge presented here in this diagnosis, is to open the discussion of the problematic and its possible solutions to allow for a more diffuse, multi-vocal, multi-modal approach favouring speculative, anticipatory and preventative thinking and to theorise sustainability more broadly beyond conventional orthodoxies. The challenge is not limited to a singular architectural perspective and precludes architectural solutions concerned with the stylistic, visual, or architectural artefact. Indeed the architectural approach would not necessitate the 'addition of something new' (Till [11]) such as material, technology or building and instead consider acts of 'invisible agency' (Till [11]) presented by spatial thinking. Emerging modes of environmental thinking such as projects $S C I B E$ and Scarcity [6] assert that 'the most appropriate solution to a spatial problem under conditions of scarcity is almost certainly not the addition of something new' (Goodbun et al. [1]) thus acknowledging the phenomenon of space as being more aligned to environmental concerns than edifice and echoing Price's observation that 'building may not be the best solution to a spatial problem' (Price [7]). Interspatiality builds on this premise, in that it recognises that the best solution for an environmental problem may not be building per se.

\section{Main objective}

\subsection{Contextualising space within theoretical paradigms}

The proposition for a new potential for environmental engagement through the conceptual formulation 'interspatiality' attempts to connect existing contemporary architectural, spatial, interdisciplinary and environmental discourses and respond to emerging spatial territories such as the 'spatial turn' identified by Henri Lefebvre and Ed Soja and new spatial territories recognised by Jeremy Till and Leon Van Schaick. The identification of spatiality and the elaboration of the environment is situated within wider thematic concerns such as Contextualism as defined by Kenneth Frampton and Thomas Schumacher, the relationship of architecture and climate and weather described by Hassan Fathy, Bernard Rudofsky, and more recently Dean Hawkes and Jonathan Hill, environmental polemics identified by Susannah Hagan and place/space controversies identified by De Certeau and Yi Fu Tuan. Interspatiality attempts to forge new connections between these spatial, environmental and interdisciplinary paradigms. 
In Lefebvre's theoretical writings, particularly the Production of Space [8], spatial production is defined as a concept as being primarily socio-politically determined, with the argument for space, limited to critical spatial practice and thinking in relation to social and political values. Much research into architecture, space and spatial determinism has been conducted since Lefebvre's spatial identifications, in the work of Edward Soja, human geographer and urban theorist. Soja elucidates in seminal publications Seeking Spatial Justice [9] and Third Space [10], a spatial theory of equity through the notion of 'spatial justice' and identifies social space as a distinct mode of critical spatial awareness. Whilst Till examines themes of spatial determinism, dependency and contingency, in publications Architecture Depends [11] and Spatial Agency [12], as opportunities for sociopolitical claims on spatial production. In Kenneth Frampton's Towards a Critical Regionalism [13] the development of thinking of context, regionalism and placemaking represents an approach of reconciliation of social, geographic and environmental specificity. Whilst Frampton acknowledges a level of environmental specificity in 'the regional inflection... range and quality of local light...or the topography of a given site', he maintains that the design process is largely limited to a 'cultural strategy' (Frampton [13]). Susannah Hagan refers to an architectural approach to environmentalism, in Taking Shape: A New Contract between Architecture and Nature [14] calling for an architectural methodology of environmental character; the 'symbiosis between natural and built environment' (Hagan [14]). In Spatial Agency [12] Awan et al. suggest that spatial production operates within the necessarily ethical and social dimension of agency, offering potential in the redefinition of architect's role as agent for change. Van Shaick proposes, in Spatial Intelligence [15] that spatial thinking may 'recast the basis of architectural knowledge' (Van Schaik 15]). Whilst more recently there has been an engagement with issues of environmentalism in historical and cultural terms, through the examination of architecture's relationship to the weather and climate, in Architecture and Climate [16] by Dean Hawkes and Weather Architecture [17] by Jonathan Hill and also the environment in The Environmental Tradition [18] and The Environmental Imagination [19]. The works of Hassan Fathy and Bernard Rudofsky Natural Energy and Vernacular Architecture [20] and Architecture without Architects [21] explore the notion of environmentally responsive architecture in both cultural and environmental terms.

Crucially the environmental dimension to spatial determinism developed within architectural theory has been neglected in favour of predominantly sociopolitical deterministic understandings of space. The relationship between space and environmental identification remains relatively unexplored. Interspatiality recognises here that there is scope for subjecting spatial theories such as Lefebvrian concepts of space to environmental scrutiny and vice versa. It also recognises a re-evaluation of the range of current spatial territories and spatioenvironmental sensibilities and connections being forged. The theory of contextualism has provided a direction for architectural production and has attempted to resolve some of the environmental and spatial concerns but these have similarly not been subjected to or developed in relation to the sustainability discourse. Interspatiality acknowledges the contextual nature and specificity of 
site and place within sustainable design and suggests that emerging spatial theories merit a radical interrogation of environmental concerns. Hawkes presupposes the potential to evolve a new understanding of the spatial relationship between architecture and environment however our comprehension of climate issues their relation and impact of sustainability concerns within architecture dimensions is deficient. There is also potential to explore environmental and cultural reciprocity in spatial terms in the work of Fathy [20] and Rudofsky [21]. This paper identifies a critical need to re-examine spatial approaches beyond the theoretical social and political spheres already identified by exploring spatial-environmental dimensions hitherto neglected. Whilst the format of this paper does not allow for discussion of these themes in significant detail it acknowledges these potentials, locates itself within them pre-empting wider research.

\section{Interspatiality}

The intention here is to expose the theoretical framework proposed by interspatiality to the problematic identified. The main objective - to test interspatiality's capacity to address issues of architectural production in relation to sustainability is focussed on urban approaches and fundamental question presented here is how does interspatiality respond to these challenges?

\subsection{Interspatiality: architecture, spatial innovation and the environment}

The three positions identified through the concept of interspatiality are as follows:

- The reconceptualisation of architecture, sustainability and the environment and the thinking of the problem through space. The development of conceptual and theoretical research, through the elaboration of new environmental dimensions; including the examination of the role and relationship of space and the environment, links between spatiality and environmental spheres, the spatialisation of the environment and spatioenvironmental perspectives.

- The reconceptualisation of environmental thinking through space and spatiality and the examination of the intersection between these two spatioenvironmental conceptual positions.

- A parallel exploration of interdisciplinary thinking and interdependencies within environmental and spatial territories. The re-evaluation of interdisciplinarity, multidisciplinary, collaborative and participatory models of working in the context of architectural, spatial and environmental production and the reformulation of the role of architecture and architects within an interdisciplinary sustainability and spatio-environmental debate.

Interspatiality identifies a new potential for environmental engagement in both architectural theory and practice and proposes the conceptual formulation to bring into connection contemporary architectural and environmental discourses and to theorise sustainability concerns more broadly. The fundamental concern of interspatiality in the initial proposition is that space, spatial design and production 
is primarily dependent, determined and conditioned by environment; that it is derived from climate and that architecture and that space has a fundamental environmental character. The conceptual formulation presupposes that architecture is interdependent; it does not exist for its own sake independent of the factors that create, define, influence and ultimately sustain it. It follows also equally that environment is dependent, determined and conditioned by space, spatial design and production. This spatio-environmental dialectic - an understanding of the reciprocity between spatiality and the environment contained here is important in realising spatial approaches to environmental solutions that support life and living in our cities in a sustainable way.

\subsection{Compensatory and retroactive approach}

This paper presents 'interspatiality' in its first stage, offering opportunities to construct new dialogues concerning architecture and sustainability, through challenging the problems identified, expanding the discussion and by reframing and anchoring architectural approaches. Interspatiality as a conceptual framework challenges compensatory and retroactive approaches. It presents spatial thinking as well-placed to develop a speculative dimension within current architectural urban debate and in offering new modes of thinking within environmental territories. Spatiality is transformative in its capacity for projective and anticipatory thinking, required in defining vast socio-economic, cultural and environmental opportunities within the urban realm. Spatial thinking is also necessarily exploratory and innovative in so far as it embodies 'potential', as Sigfried Giedion observes when referring to space as 'pure' potential, in Space, Time and Architecture [22] and Mechanization takes Command [23].

Interspatial thinking viewed as 'reconciliation' (Van Shaik [15]) has the capacity to engage with new modes of thinking - such as relational, convergence, connectivity and interdependence. Giedion considers space as a tool or device for thinking and a concern for ' new and manifold relations' (Giedion [23]) and it is proposed that interspatiality can connect with emerging architectural and spatial approaches; such as notions of agency and contingency acknowledged by Till, 'Integral Theory' presented by Buchanan in the Big Rethink [24], relational approaches such as the interconnectedness of systems, ecological, social and economic on a global scale, explored by Tyscukuk and Smith in the Interdependence Day Project [25] and spatio-epidemiological approaches identified by Van Shaik [15]. Interspatiality can bring into relationship different modes of knowledge and adopt positions that embrace diverse and conflicting interests, agendas and debates, that result from the 'contradictory certainties' (Hannigan cited in Guy [2, p. 138]) that characterise urban controversies.

\subsection{Commodification, 'iconism' and homogeneity}

Interspatiality challenges notions of homogeneity, commodification and iconism and proposes that the key to addressing challenges in terms of urban sustainability lies in the redefinition of architectural production viewed as 'subject' in lieu of object, in spatiality viewed as time-bound and localised and in 'placeness' as 
distinct from built or urban form. Spatiality confronts the tendency for iconism in its concern for invisible structures such as 'in-between spaces' recognised as the public realm. Interspatiality references Frampton's approach to the shaping of urban space as 'place-form', suggesting a contextually responsive and 'place conscious' spatial approach in direct opposition to subsumed notions of 'global commodification [and] homogenisation of the urban realm' (Till 11]) and dominated by the imposition of 'standard formal solutions with little regard for local conditions'(Till 11]).

Interspatiality acknowledges the controversy of space and place or 'genius loci' explored by Michel De Certeau, amongst others, who identifies 'space as a practiced place '(De Certeau [26]). This interdependency is relevant - 'space occurs as the effect produced by the operations that orient it, situate it, temporalize it, and make it function in a polyvalent unity of conflictual programs or contractual proximities' (De Certeau [26]). In Building, Dwelling, Thinking, Heidegger discusses interdependency and relational proximities of space and 'accordingly, spaces receive their essential being from locales and not from 'space' (Heidegger 27]). Whilst anthropologist Yi Fu Tuan asserts in his influential work, Space and Place that two notions are of place and space are co-dependent - 'it is impossible (however) to describe place without introducing explicitly spatial concepts' (Tuan [5]). The notion is reflected in Hagan's identification of differentiation which 'refers to recognition of, and response to, the particularities of geographic and cultural place' (Williamson et al. [28]).

\subsection{Technology, efficiency and the environment}

Interspatial thinking allows us to theorise sustainability concerns more broadly beyond simply a battle between building physics and technology and tackle the problematic of the environment. It defines an approach which expands the debate beyond conventional orthodoxies of technology and consensual definitions of 'green' building to define a more meaningful engagement and integration of environmental issues. It defines the role of the environment at the forefront to the discussion reflecting Cedric Price's claim that 'architecture must concern itself continually with the socially beneficial distortion of the environment' (Price [29]) and suggests that the phenomenon of space is aligned to environmental concerns rather than edifice. It is Lefebvre who elucidates the environmental role of space when acknowledging complex sustainability agendas such as the environment 'converge into space' (Lefebvre 8]). Lefebvre asserts that scarcity of resources the 'using up of resources' can be seen as both 'spatial and local' (Lefebvre [8]) and presciently observes space 'presupposes confrontation and indeed this has already emerged in the problems of the 'environment' (Lefebvre [8]). Furthermore interspatiality has the capacity to anchor architecture and the tendency within spatial discourse towards abstraction - such as can be seen in the examples of parametric and generative computational approaches, through the actuality of the environment and environmental particulars such as place. 


\subsection{Autonomy and disconnection}

Interspatiality challenges the notion of autonomy presented here, and calls for the repositioning of the role of architecture at the very centre of the interdisciplinary and sustainability debate, as protagonist through the redefinition of spatiality and its role within a sustainable social, economic and environmental future. Architects are uniquely placed, through the deployment of interspatiality, to engage with wider controversies and manage the confluence of a multiple approaches and factors in an integrative and reconciliatory way. The context of diverse and often complex interdisciplinary agendas necessarily places the architect centrally and it is at the intersection of the resultant nexus conditions seen in urban space that architecture's contribution becomes vital. Interspatial thinking is well-equipped to advance new forms of synthesis as spatial design necessitates cohesive and synthetic approaches within divergent and conflicting debates, particularly those in relation to multifarious and complex urban environmental questions.

Spatiality is necessarily interdisciplinary - a notion echoing Lefebvre's assertion that space 'cannot be the product of a single person' (Till [11]) and Soja's claim that 'we are all producers of space' (Soja [10]). Spatiality is a mode of thinking that simultaneously brings together many subjects to bear upon it and a practice, involves many authors and is the responsibility of many fields and disciplines. This shared interest becomes manifest, as noted by Lefebvre in 'the collective ownership and management of space founded on the permanent participation of the interested parties with their multiple, varied and often contradictory interests' (Lefebvre [8]). Lefebvre asserts that contradictions of space demand new opportunities for synthesis and integration. Opportunities are produced by 'multiple and contradictory forces' (Till [11]) and as such architecture 'assimilates contradictions' (Goodbun et al. [1]) both physical and non-physical concerns, often 'divergent and irreconcilable' (Guy [2, p. 138]). The discussion of spatiality and spatial design crosses boundaries of traditional design through the concept of 'connected space', as Matthew Barac and Lesley McFadyen observe and is able to connect 'not only circumscribed disciplines with other discourses but also things and places with ideas and activities' (Barac and McFadyen [30]).

Till argues in Spatial Agency that the role of architecture is wider than the conventional limits of the autonomy that suffuses architectural praxis. Interspatiality can bring into relationship multi-disciplinary spatial territories such as the spatial turn and anchor architecture within spatial dialogues shared by other disciplines. The view that new modes of spatial thinking can open discourse is relevant since 'when you advocate something outside your discipline...like people of communities - it opens up the possibilities in your own discipline' (Heathcote cited in Kidder [33]). Interspatial thinking provides us with the prospect for a more expansive, diffuse and collective engagement with environmental concerns and the prospect of 'integrating or bringing into relationship, knowledge fragmented between specialisms' (Buchanan 32]). It uncovers the possibility 'to trace new disciplinary boundaries in the world, practically and conceptually' (Goodbun et al. [1]) and 'beyond narrow technical aesthetic or professional interests' (Sirowy 
[31]). Interspatiality and interspatial thinking has the capacity to reconfigure relationships between disciplinary modes of thinking, working and practice and can facilitate new spatial-environmental identifications, architectural and design conceptualisations that are more responsive to contemporary sustainability and environmental realities and repositions the role of architecture and architects within a wider interdisciplinary context at the core of the sustainability debate.

\section{Conclusion}

The paper presents 'interspatiality' as a conceptual formulation of environmental issues and offers the opportunity for the forging of a new relationship between architecture and the environment, the re-evaluation of spatial territories and the development of environmental and interdisciplinary thinking. It proposes that spatial thinking can bridge the separation between architecture and environmental concerns in an interdisciplinary context. The significance of interspatiality is that it provides a conceptual key to address key sustainability issues such as urbanisation. The co-evolution of the two propositions presented here; spatioenvironmental and interdisciplinarity can elicit new perspectives on architecture and urbanism within a much larger sustainability discourse. As a conceptual formulation, it assimilates numerous cross-disciplinary environmental approaches and serves as a manifold for integration and reconciliation of contradictory and oppositional positions that characterise urban conditions. Interspatiality as an approach can provide a focus for interdisciplinary thinking and practice through the examination of connections and interactions between spatial and disciplinary territories and represent spatiality from an interdisciplinary perspective offering the prospect of integrating different modes of knowledge and environmental positions.

It is hoped that interspatiality can generate a credible framework for wider research and dialogue-one that is robust, flexible, diffuse, multi-dimensional, interdependent and participatory and can bring into relationship a wide variety of diverse reflective and alternative approaches, encompassing many disciplines and reconciling opposing agendas. The formulation as introduced here begins to frame a territory which looks to the development of an overarching core understanding of spatial-environmental approaches and a new spatial methodology of environmental character, where space and spatial identifications and insights act as a vehicle for analysis and in the development of models, design strategies, methodologies and conceptual 'toolkits'. The conceptualisation of 'interspatiality' - the spatialisation of the environment and interdisciplinarity, seeks to forge a new model of 'integral sustainability', signalling a more unifying, collective, cohesive, inclusive and reconciliatory architectural approach and referencing Buchanan's (Buchanan [24]) aspiration for a more robust, productive, creative and 'complete architecture' - one scripted to suit the emerging global reality and also Van Schaik's call to architecture when referring to new forms of spatial thinking - 'can architecture become whole once again?' (Van Shaik [15]). 


\section{References}

[1] Goodbun, J., Iossifova, D. \& Till, J., Scarcity: Architecture in the Age of Depleting Resources, Architectural Design. John Wiley and Sons, pp. 1114, 19, 30, 39, 132, 2012.

[2] Guy, S. (2013), Pragmatic Ecologies in Harrison, Ariane Lourie, Architectural theories of the Environment, Posthuman Territory, Routledge, pp. 140-141, 2013.

[3] Guy, S. \& Farmer, G, Reinterpreting Sustainable Architecture - The Place of Technology, February 2001, Journal of Architectural Education, p. 139, 2001.

[4] Lefebvre, H., The Production of Space, (trans. D Nicholson-Smith) Oxford: Basil Blackwell Publishing, p. 326, 1974.

[5] Tuan, Y., Space and Place, The Perspective of Experience, The Minnesota Press, p. 136, 2001.

[6] Scarcity - SCIBE - Scarcity and Creativity in the Built Environment 2010, http://www.scibe.eu

[7] Price, C., Architectural Association Works 2, London: Architectural Association, p. 107, 1984.

[8] Lefebvre, H., The Production of Space, (trans. D Nicholson-Smith) Oxford: Basil Blackwell Publishing, pp. 329, 371, 422, 1974.

[9] Soja, E., Seeking Spatial Justice, Minneapolis: University of Minnesota Press. Third Space, 2010.

[10] Soja, E., Third Space, Malden (Mass.): Blackwell, 1996.

[11] Till, J., Architecture Depends, Cambridge, MA: MIT Press, pp. 15, 16, 29, 126, 127, 2009.

[12] Awan, N., Schneider, T. \& Till, J., Spatial Agency, Other Ways of Doing Architecture, London: Routledge, 2011.

[13] Frampton, K., "Towards a Critical Regionalism: Six points for an architecture of resistance", reprinted in H. Foster (ed.), The Anti-Aesthetic: Essays on Postmodern Culture, Bay Press, pp. 21, 27, 1983.

[14] Hagan, S., Taking Shape: A New Contract Between Architecture and Nature, Architectural Press, p. xi, 2001.

[15] Van Shaik, L., Spatial Intelligence, New Futures for Architecture Architectural Design Primers, John Wiley and Sons, pp. 27, 46, 63,79, 171, 2008.

[16] Hawkes, D., Architecture and Climate: An Environmental History of British Architecture-1600-2000, Routledge, 2012.

[17] Hill, J., Weather Architecture, Routledge, 2012.

[18] Hawkes, D., The Environmental Tradition, studies in the architecture of the environment, E\&FN Spon, 1996.

[19] Hawkes, D., The Environmental Imagination, technics and poetics of the architectural environment Taylor and Francis, 2007.

[20] Fathy, H., (Editor W. Shearer) Natural Energy and Vernacular Architecture: Principles and examples, with reference to hot arid climates, University of Chicago Press, 1986. 
[21] Rudofsky, Bernard (1964), Architecture Without Architects: A Short Introduction to Non-pedigreed Architecture, Thames \& Hudson.

[22] Giedion, S., Space, Time and Architecture: The Growth of a New Tradition Harvard University Press, p. 30, 1941.

[23] Giedion, Sigfried (2010) Mechanization takes Command, A Contribution to Anonymous History, Oxford University Press, p. 3, 1948.

[24] Buchanan, P. The Big Rethink, Towards a Complete Architecture \& Integral Thinking, Essays, January 2012-May 2013, The Architectural Review. www.architectural-review.com/the-big-rethink

[25] Tyszczuk, R., \& Smith, J., (2009), The Interdependence Day Project: Mediating Environmental Change, The International Journal of the Arts in Society. Interdependence Day Project 2006, http://www.open.ac.uk

[26] De Certeau, M., The Practice of Everyday Life, University of California Press, p. 117, 1980.

[27] Heidegger, M., Building, Dwelling, Thinking in Poetry, Language and Thought, (trans. A HofStadter) New York, Harper and Row, pp. 356, 1952.

[28] Williamson, T., Radford A., Bennett, H., (2003) Understanding Sustainable Architecture, Spon Press, p. 130, 2003.

[29] Price, C., Architectural Association Works 2, London: Architectural Association, p. C1, 1984.

[30] Barac, M. \& McFadyen, L., Connected Space, Home Cultures, Volume Four Issue Two, The Journal of Architecture, Design and Domestic Space, 2007.

[31] Sirowy, B., Phenomenological Concepts: Architecture, Towards a UserOriented Practice, Arkitekthogskolen i Oslo, p. 261, 2010.

[32] Buchanan, P., The Big Rethink, Integral Theory, Essay, March 2012 The Architectural Review, 2012b.

[33] Kidder, P., Gadamer for Architects, Routledge, p. 95, 2012. 